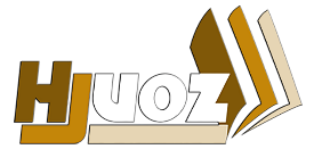

hjuoz.uoz.edu.krd p-ISSN: 2410-7557 e-ISSN: $2518-5128$
كَوْارا زانستيّن مروّفايهتى يا زانكوّيا زاخوّ

مجلة العلوم الانسانية لجامعة زاخو

Humanities Journal of University of Zakho (HJUOZ)

Vol. 5, No. 1, pp. 185-199, March-2017

\title{
التدقيق التسويقي ودوره في تفعيل تسويق المنتجات الجامعية: انموذج مقترح
}

\author{
محمد حويش علاوي الشجيري
}

قسم المحاسبة، كلية الادارة والاقتصاد، الجامعة العراقية، بغداد- العراق ( malshujairi@yahoo.co.uk)

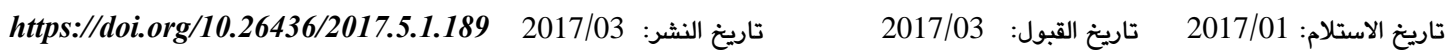

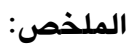

يتناول البحث الحالي مفهوم وتطبيقات التدقيق التسويقي في المنظمات الخدمية غير الهادفة للربح بشكل عام وفي الجامعات

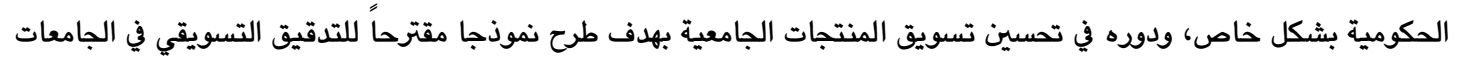
العراقية الحكومية يتناول المفاهيم والمنافع والهياكل واليات العمل التي تساهم في تفعيل مفهوم الجامعة المنتجة لتجاوذ الازمة

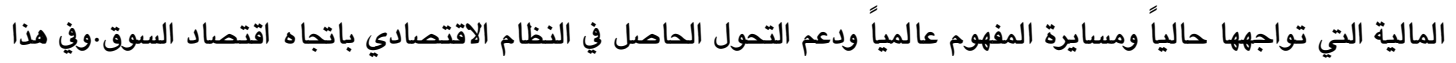

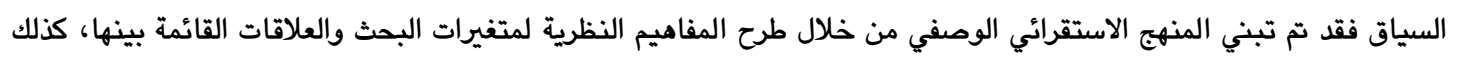
في إطار وصف طبيعة وممارسات التسويق الجامعي في مجال عينة البحث. فيما تم توظيف المنهج الاستنباطي لبناء انموذج معياري مقترح قائم على نتائج المنهج الاستقرائي كأساس لتوظيف مفهوم التدقيق التسويقي في تفعيل تسويق المنتجات الجامعية. وقد

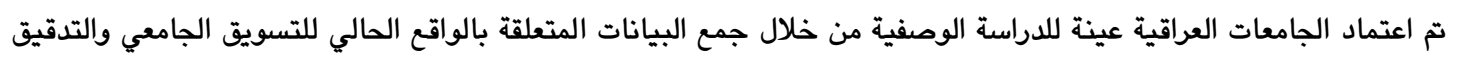

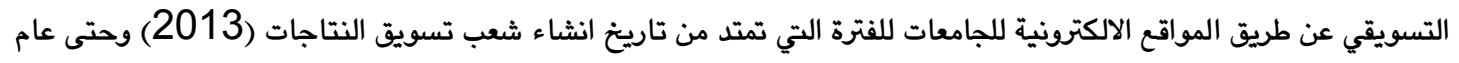

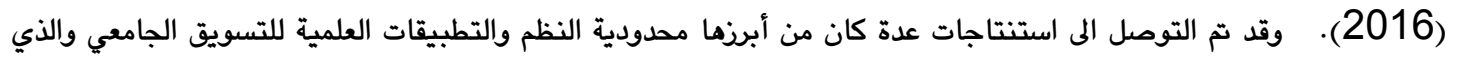
يعكس ضعف إدراك الادارة الجامعية لمفهوم واهمية واليات التسويق الجامعي الفاعل، فضلا عن غياب تام لمفهوم وتطبيقات

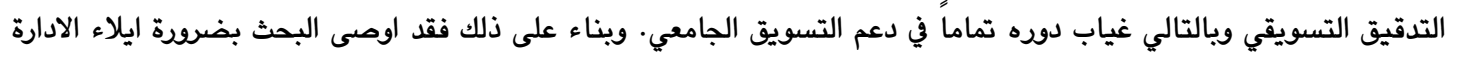

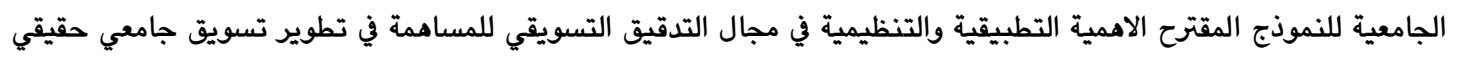

فاعل وكفء.

\section{الكلمات الدالة: التسويق الجامعي، التدقيق التسويقي، الجامعات العراقية الحكومية.}

والشمايلة، 2007). لذا تسارعت وتيرة التفكير في اممية وضع البدائل

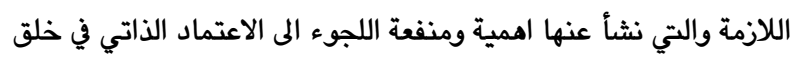

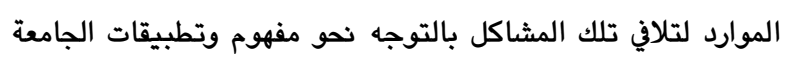
المنتجة او (الجامعة الاقتصادية) لتطوير وتعزيز مصادر تمويلها

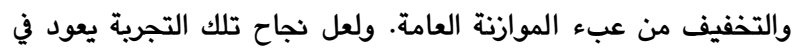
جزء كبير منه الى النجاح في ادارة تسويق المنتجات الجامعية. والتي

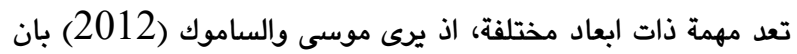
تسويق المنجز البحثي والعلمي تعتمد على عملية إحداث التغيير في

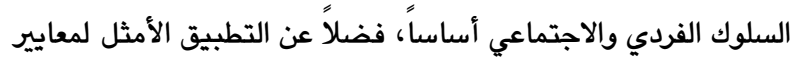

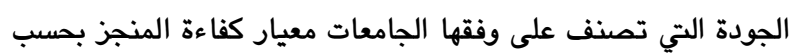

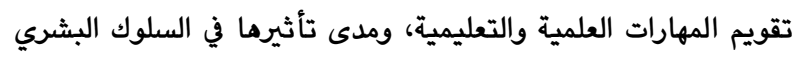
ومخططات التغيي والتي تتطلب البحث عن استراتيجية واقعية لتسويق المنجزات والأفكار والإبداعات والطاقات. وان نجاح هذه الوظيفة يساهم

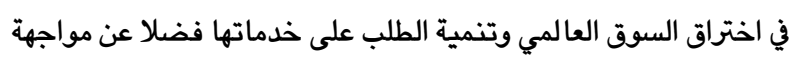

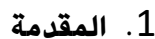

يتناول البحث الحالي اشكالية واقعية مهمة على المستوى العالمي وتزداد اهميتها البالغة على المستوى المحلي العراقي، اذ تواجه الجامعات العراقية ازمة حقيقية في تمويل انشطتها المختلفة نتيجة الازمة المالية الخانقة التي يعاني منها الاقتصاد العراقي والتي تتضح ملامحها في عجز الموازنة الكبير عن تغطية النفقات العامة ومنها النفقات العامة للمؤسسات التعليمية، مما ينعكس سلبا في قدرتها على الاستمرار

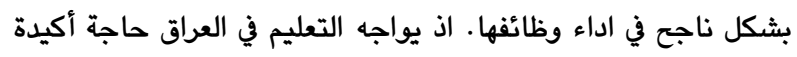

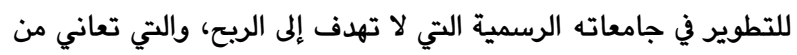
عجز مستمر في موازناتها، لا سيما ان هذه الجامعات الرسمية مع ازدياد

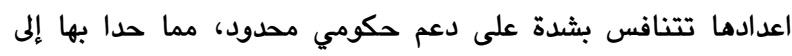
خصخصة بعض أنشطتها وابتكار برامج جديدة مثل برنامج التعليم

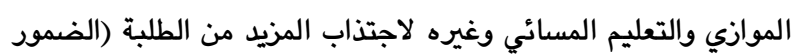


ظل الظروف الاقتصادية الحرجة التي يمر بها العراق، فضلا عن مسايرة التطورات العالمية والاقليمية في مجال الجامعة المنتجة او الاقتصادية. وفي إطار ذلك فقد تم اتباع المنهج الاستقرائي الوصفي في عرض وتحليل متغيرات البحث وعلاقاته على المستوى النظري بهدف الوصول الى تبريرات منطقية واقعية للمفاهيم والاهداف والمنافع والعلاقات الرابطة. اما على المستوى الميداني للبحث فقد ثم الانطلاق من نتائج التحليل النظري الوصفي كمقدمات منطقية لبناء انموذج عملي واقعي لما يجب ان يكون عليه التدقيق التسويقي الذي يسامم في رفع وتطوير جودة التسويق الجامعي في العراق من خلال توظيف المنهج الاستنباطي - المعياري وقد تم تناول موضوع البحث في ظل ذلك من خلال خمسة محاور، تناول الأول الإطار المنهجي للبحث، اذ تناول المحور الثاني مراجعة الادبيات السابقة، فيما تناول المحور الثالث الإطار النظري لمتغيرات وعلاقات البحث. اما المحور الرابع فقد تناول دراسة ميدانية لواقع التسويق الجامعي والتدقيق التسويقي في الجامعات العراقية، اما المحور الخامس فقد تناول انموذج البحث المقترح، اما المحور الاخير فقد تناول أبرذ

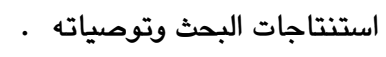
مراجعة الادبيات السابقة 1- تناولت دراسة (أبو نبعة، 2004) التي استهدفت بيان مفهوم التسويق الحديث وتطبيقاته في الجامعات الأمريكية والإجابة عن السؤال المتعلق فيما إذا كانت الجامعات في الدول النامية بحاجة إلى تطبيق هذا المفهوم. وخلصت الدراسة إلى ضرورة تبني مفهوم التسويق الحديث في جامعات الدول النامية والعربية على أنه سبيل لتطور التعليم العالي

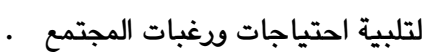
اما دراسة (راضي وابراهيم ، 2010) فتناولت تقييم واقع تسويق الخدمات التعليمية في كلية المأمون الخاصة في بغداد، وقد ارتكزت الدراسة على تساؤلات أساسية تتعلق بمستوى قيام الكلية بجودة تسويق خدماتها، وتقييم الواقع التسويقي للخدمات الجامعية التعليمية والمساندة والتكميلية من منظور العاملين والطلبة، وقياس مستوى خريجي الكلية من منظور أصحاب العمل، اذ تؤكد على ان نجاح الجامعات في تقديم خدماتها التعليمية والخدمات المرتبطة بها يرتبط بعاملين أساسيين هما: تحقيق المستوى المطلوب من الجودة للخدمات التعليمية والخدمات المرتبطة بها. إذ لا يكفي أن تقدم الجامعة خدمات تعليمية متميزة بل ينبغي أن يكون المستفيدون على علم بمستوى جودة هذه الخدمات التي تقدمها الجامعة، وهذه قاعدة تسويقية أساسية (قاعدة مصيدة الفئران. اما (Loya,) 2011 (فيؤكد على ان الادبيات تعاملت بشكل اساسي مع الجوانب النظرية والفكرية للتدقيق التسويقي، وهناك اتفاق حول

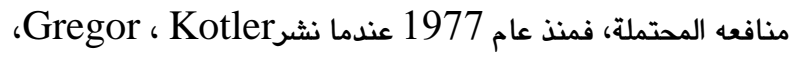
“The Marketing audit كتابه بعنوان مand Rodgers
المنافسة الشرسة وتحسين المركز التنافسي لها وهو ما يساهم في مجموعه مسايرة المتغيرات البيئية. ونتيجة لذلك اصبحت الجامعات بحاجة ماسة لتبني توجهات ادارية جديدة تمكنها من التفاعل الايجابي مع المتغيرات البيئية المختلفة من خلال استثمار الفرص المتاحة ومواجهة التحديات التي تواجهها. وهو ما يستدعي انشاء ودعم وظيفة التدقيق التسويقي، والتي تساهم في تفعيل الوظيفة التسويقية للجامعة المنتجة، اذ يؤكد) 2012 Chirla (على ان التدقيق التسويقي يوفر منافع مهمة ورئيسة لتفعيل التدقيق التسويقي، اذ يسامم في تقويم وتحسين الانشطة التسويقية المختلفة للمنظمة فضلا عن مساممته في نجاح تبني توجه تسويقي استراتيجي فضلا عن العديد من مزايا

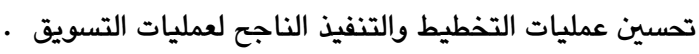
لذا يمكن تلخيص إثكالية البحث الحالي في جملة من التساؤلات البحثية الاتية:

ماهية مفهوم وطبيعة العلاقة التفاعلية بين التدقيق التسويقي وتسويق

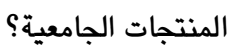
1. ما هو دود التدقيق التسويقي في تفعيل تطبيقات الجامعة المنتجة. 2. ماهي الاجراءات التنظيمية والتطبيقية لممارسات التدقيق التسويقي الناجع في الجامعات المنتجة؟ 3. ما هو واقع التسويق الجامعي والتدقيق التسويقي في الجامعات العراقية؟ 4. ما هو طبيعة تنظيم واليات وتطبيقات التدقيق التسويقي الذي يساهم في تقويم وتفعيل الاداء التسويقي الجامعي للمؤسسات التعليمية

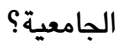
وفي سياق ذلك فان البحث الحالي يهدف على المستوى النظري الى بيان مفهوم وطبيعة واليات عمل التدقيق التسويق، وكيفية مساهمته في تفعيل كفاءة وفاعلية تسويق المنتجات الجامعية. اما على المستوى الميداني فان البحث الحالي يستهدف تحديد ملامح واقع كل من هياكل واليات ونشاطات التسويق الجامعي والتدقيق التسويقي كمقدمة لتحديد نقاط القوة والضعف ويالتالي الانطلاق لوضع انموذج مرجعي متكامل يوضح مفهوم واهداف وهياكل واليات وانشطة التدقيق التسويقي التي تساهم في تفعيل التسويق الجامعي لخدماتها لذا تنبع اممية البحث من العمل على رفع ادراك الادارات الجامعية العراقية بمفهوم واهمية التدقيق التسويقي لتفعيل واقع تسويق المنتجات الجامعية من جهة ، والمساممة في وضع انموذج عملي لكيفية توظيف مفهوم التدقيق التسويقي والياته ومياكله العملية والتنظيمية موضع التطبيق من جهة اخرى للمساممة الفعلية للبحث في تشجيع ووضع التدقيق التسويقي محل التطبيق نظرا للدور الكبير الذي يمكن ان يساهم به في تجاوز الجامعات العراقية الازمة المالية التي تعانيها من جهة وفي رفع مساهمتها في التخفيف من كاهل الموازنة العامة للدولة في 
لذا ينطلق البحث الحالي من النتائج التي توصلت اليها تلك الدراسات كأساس لوضع انموذج عملي للتدقيق التسويقي لدعم وتفعيل تطبيقات التسويق الجامعي على وجه التحديد.

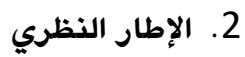

1.2. تسويق المنتجات الجامعية

يشكل التسويق أحد الانشطة الاساسية التي تقوم بها المنظمات الحديثة، كما يعد محورا استراتيجيا لأي مواجهة بين المنظمة والبيئة التي تتواجد فيها. فالتسويق بحسب الجمعية الامريكية للتسويق بعدئ (2009) هو " عملية التخطيط ووضع المبادئ والدعاية والتوزيع للأفكار والبضائع والخدمات من اجل معاملات تجارية ترضي رغبات كلا الطرفين (العتيبي، 2015: 31). وقد أدت التطورات التي حدثت في عالم المعلومات إلى إدراك أهمية التسويق في الجامعات ومراكز المعلومات، ليربط بصفة مباشرة أو غير مباشرة منتوجات المعلومات بمستخدميها، ومن ثم تحقيق ريح مادي عن طريق إرضاء المستفيدين واشباع حاجاتهم من المعلومات ويما يساهم في زيادة عدد المستخدمين وزيادة الدعم الذي يستخدم في تنمية مصادرها وتطوير خدماتها أو التوسع في مبانيها وغير ذلك فضلا عن انه يكسب الجامعة سمعة طيبة ويعزز صورتها في أوساط الباحثين والدارسين والمجتمع عامة (احمد

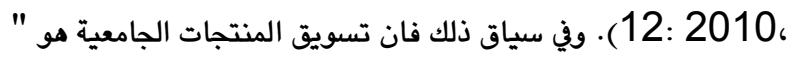
عملية تخطيط وتنفيذ وترويج لما تقدمه الجامعة من خدمات للمستفيدين من جميع افراد المجتمع بهدف اتمام عملية التبادل حيث تتعرف الجامعة على حاجات المستفيدين الحاليين والمرتقبين من خدماتها ويتم تطويرها بما يتفق وهذه الحاجات بالشكل المناسب ومستوى الجودة المناسبة وفي الوقت المناسب ويأقل تكلفة ومحصلة الامر تمكين الجامعة من القيام بدورها في خدمة المجتمع" (العتيبي،

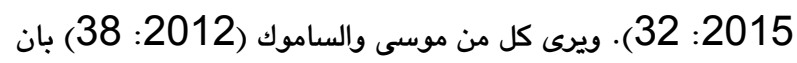
الخدمات الجامعية يمكن ان تشتمل على المنجزات العلمية، والنتاجات البحثية، والطاقات التي ترفد سوق العمل بالتخصصات العلمية المختلفة، والخدمات الاستشارية، والإسهامات الثقافية والفنية والإبداعية والفكرية، وغير ذلك.

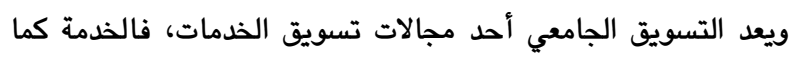
يراها (كوتلر، 2005) بانها " نشاط او منفعة معروضة للمبادلة وهي في الاساس غير ملموسة ولا ينتج عنها اي كمية فالخدمة يمكن ان تكون مرتبطة او غير مرتبطة بمنتج مادي (العتيبي، 2015: 29). اذ ملاد يتمثل التوجه التسويقي للمؤسسات التعليمية في توجيه أهداف واستراتيجيات وأنشطة وخدمات هذه المؤسسات وفقا لاحتياجات ومتطلبات عملائها المستفيدين من خدماتها سواء داخل هذه المؤسسات أو خارجها، وذلك من خلال تطبيق المفاهيم والأساليب التسويقية الحديثة المتعلقة بعناصر المزيج التسويقي لخدمات هذه المؤسسات (الحريري، 2009 : 12). ويالتالي فان التوجه التسويقي
Comes of Age” تركز البحث في المفهوم وتوفير الاداة المنطقية ، لهذا النوع من التدقيق ومنافعه من خلال دراسات الحالة والامثلة لعمليات التخطيط التسويقي وان هناك افتقار كلي لدراسة تجريبية ثاملة لتطبيق التدقيق التسويقي في الادبيات المنشورة. وان هناك بعض المراجع الجامعية تعرض التدقيق التسويقي كطريقة للتقويم والية للرقابة وتوصي بضرورته كجزء من عملية التخطيط التسويقي، الا ان ذلك كان دون وجود دعم له من خلال تطبيق عام للتدقيق التسويقي. اما دراسة (Radulescu,) 2012 (فقد تناولت تحديد المراحل الرئيسة لمؤشرات تحليل السوق التي ستستخدم في التحليل الشامل الذي يسمح للشركات بأنشاء استراتيجية تسويقية مناسبة، تنطلق من اممية التدقيق التسويقي كأداة تقيس القيمة والمخاطر وفاعلية الجهود التسويقية، والذي يعد المرحلة الاولى المهمة في عملية التخطيط التسويقي من خلال تقييم المواقف الحالية والمتوقعة للشركة في المجال التسويقي، ولتحقيق التدقيق التسويقي الفاعل فان المدقق يجب اولا ان يعرف السوق الذي تعمل فيه الشركة. اما دراسة (Denisa \& Jaroslav,) 2013 (فقد تناولت التدقيق التسويقي كأحد عوامل النمو والنجاح المستقبلي للمنظمة، اذ يمكن من خلاله ان يصبح النشاط التسويقي ذو توجه متجدد في ادارة الاعمال، اذ يساعد في مراجعة الهياكل التسويقية ويالتالي امكانيته في المساممة في تجديد نشاطها بشكل عام وليس فقط تحسين النشاط التسويقي، لذا فان الدراسة اهتمت بمتطلبات وتنفيذ التدقيق التسويقي بشكل ناجح في الشركات السلوفاكية. اما دراسة (شناي ، 2015) فقد تناولت تأثير التدقيق التسويقي في تحسين الاداء التسويقي في المنظمات الخدمية ، اذ تنطلق الدراسة من ان التدقيق التسويقي يساعد في ايضاح الاليات العملية للإدارة في كيفية تحسين اداءها التسويقي ، اذ انه يذهب ابعد من مجرد تقييم الاداء التسويقي للبحث في ابعاد اخرى اوسع بكثير من مجرد التقييم ويذلك فهو يساهم في تقديم المقترحات لتشمل رسالة المنظمة واهدافها واستراتيجياتها التسويقية وعناصر البيئة التسويقية وغيرها من العناصر والتي قد تسفر عن تغيير تلك العناصر وتطوير عمل المنظمة الداخلي والخارجي. وفي هذا السياق فان الدراسات المشار اليها اعلاه وجميع الدراسات التي استند اليها البحث الحالي تشير الى اهمية التدقيق التسويقي العملية في تفعيل النشاط التسويقي للمنظمات بشكل عام والمنظمات الخدمية ومنها الجامعات على وجه التحديد، والذي ينعكس بالمجمل في النشاط بتشي الكلي للمنظمة وتحسين استراتيجياتها وجودة خدماتها وتحسين علاقاتها بالمجتمع من خلال تحسين وسائل التواصل وفهم متطلباته المتغيرة وتحقيقها بأفضل الوسائل والتي تنعكس بمجملها في تحقيق غايات المنظمة ودعم مصادر التمويل المختلفة. 
1. مهارة الافراد مقدمي الخدمة: اذ ان جودة اداء الخدمة تختلف من .

$$
\text { فرد لأخر ومن وقت لأخر. }
$$

القيمة المضافة للخدمات المساعدة: تعد هذه الخدم: الخدمات أحد

الاليات التنافسية التي تميز جودة خدمات معينة عن اخرى. لذا تتمثل عناصر المزيج التسويقي الجامعي كتسويق خدمات بالآتي (العتيبي، 2015: 37-38):

تخطيط الخدمات: ويشمل كل من تصديد مزيج الخدمات المطلوب تقديمها الى الزيائن وعمق واتساع المزيج الى جانب دراسة وتطوير الخدمات الجديدة او تطوير او الغاء الخدمات الحالية.

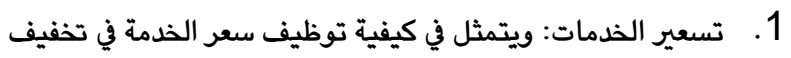

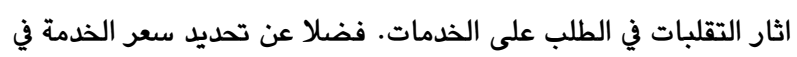
ضوء اتجاهات الطلب على الخدمة وظروف المنافسة في السوق والذي يلائم الخدمات الجامعية أكثر من غيره. 2. توزيع الخدمات: ضرورة استخدام قنوات التوزيع المباشر لإعطاء فرصة أكبر في تقديم خدمات أفضل من خلال قنوات الوسطاء. فضلا عن وضع وتشغيل قنوات التغذية الراجعة في توفير المعلومات التي تساعد في تحسين اداء الخدمة. 3. ترويج الذدمات: يستخدم الاعلان عن الخدمات بما يتلاءم والمنافع والعوائد التي يبحث عنها المستهلك، فضلا عن ضرورة تركيز الاعلان حول تحسين اتجاهات العاملين وانطباعاتهم تجاه اداء الخدمة المقدمة ويما يعزز المركز التنافسي، كما يلعب البيع الشخصي دورا مهما في التسويق الجامعي الى جانب ضرورة الاهتمام بالدعاية أكثر من الاعلان في مثل مذه المنظمات لما يعده الزبون أكثر موضوعية من

الاعلان. 4. ولا شك فأن الحصول على الميزة التنافسية للجامعة أصبح مرهوناً بمدى توجهها نحو التسويق المعاصر بكل تطبيقاته وأبعاده المتعددة بداية بدراسة وتحديد احتياجات العملاء (أفراد ومنظمات)

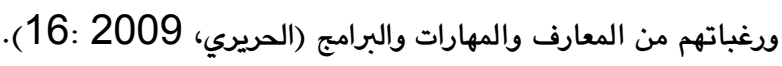
ويالتالي فان للتسويق الجامعي فوائد مهمة ورئيسة، اذ يؤكد كل من

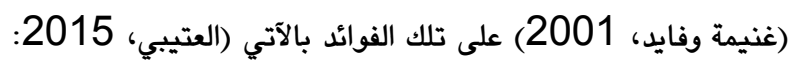

مساعدة الجامعة على توفير الحلول للمشكلات التي تواجه مجتمعها بالإضافة الى مساعدتها في استكمال العملية التعليمية والبحثية التي تقف في الغالب عند حدود النتائج دون الوصول الى تطبيق تلك النتائج

او الاستفادة منها.

1.المساممة في تكامل وظائف الجامعة وخدمة الوظيفة التعليمية

$$
\text { والاستفادة من مواقع العمل والانتاج. }
$$

2. رفع قيمة دود الاستاذ الجامعي من خلال ربطه بواقع ومشكلات

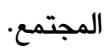

للجامعة يتمثل في توجيه اهداف واستراتيجيات وانشطة وخدمات الجامعة وفقا لاحتياجات ومتطلبات عملاءما المستفيدين من خلال تطبيق المفاهيم والاساليب التسويقية الحديثة (العتيبي، 2015: 32). لذا فان أبرذ المكونات الاساسية للتوجه التسويقي الجامعي تتمثل في (نفس المصدر، 33 :33): 2015 : 2015 التسويق المتكامل: يتمثل في التكامل والتنسيق بين مختلف ادارات واقسام الجامعة من جهة، وعناصر المزيج التسويقي وخدمات الجامعة

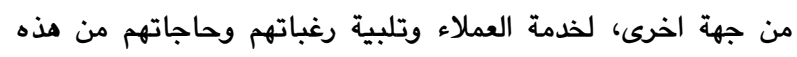
البرامج والخدمات. التسويق الداخلي: وهو يمثل أحدث الابعاد الاساسية لتسويق الخدمات نظرا لطبيعة وخصائص الخدمات التي تميزها عن السلع والتي من أبرزها التلازمية في الخدمة بمعنى صعوية الفصل بين الخدمة ومقدمها اذ انها تستهلك بمجرد انتاجها مما يتطلب من الجامعة الامتمام

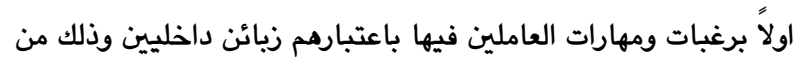

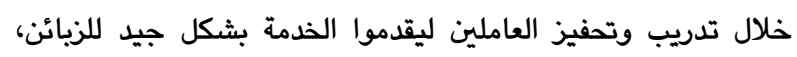
ويذلك يسبق التسويق الداخلي التسويق الخارجي للخدمات. إن تحقيق الإبداع في صياغة المنتج الجامعي يتطلب ضرورة إعداد

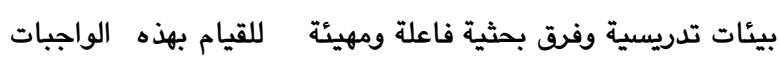
بشكل يليق بمكانة الجامعة في المجتمعات الحديثة، ومن هنا نجد ان كل من (Stan Davis; Christopher Meyer) يؤكدان في كتابهما ثروة المستقبل على أولوية رأس المال البشري، الذي سيقود الى صراع عالمي حول المبدعين ، وكنتيجة لهذا تفقد الأصول

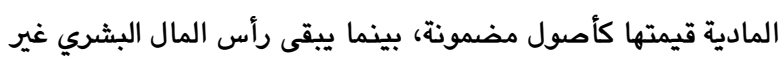

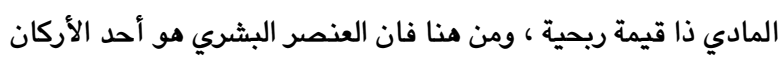
الرئيسة في صياغة استراتيجيات التسويق الجامعي الناجع (موسى وابتى والساموك ، 2012 : 43-44). لذا فان المفهوم الأساسي لجودة الخدمات الجامعية يجسده الهدف الذي تسعي الجامعة إلى تحقيقه والوصول إليه من خلال مخرجات التعليم، وهذا الهدف يتم تحقيقه من خلال تكامل وتفاعل جميع العناصر التنظيمية باتجاه تحديد حاجات المستفيد وتلبيتها بكفاءة وفاعلية. أن جودة الخدمة الجامعية هي مسؤولية جميع العاملين في الجامعة، ويشارك الطلبة أيضا في تحقيق هذه الجودة عن طريق المشاركة، وان النظام الأكاديمي والنظام الإداري، والنظام المالي تتكامل جميعها بجميع عناصرها لتحقيق الإسهام الفاعل في بناء جودة الخدمة التعليمية، وهي تعمل على توفير ما يلزم من موارد مادية ومالية ويشرية لهذا الغرض لإسهاء

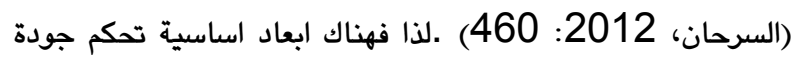
التسويق الجامعي كتسويق خدمات، وتتمثل تلك الابعاد بالآتي (العتيبي، 2015: 36-37): سمعة مقدم الخدمة: وهي مؤشر مهم في تسويق الخدمات المهنية على وجه الخصوص والتي تتميز بالغالب بعدم امكانية ردها لمقدم الخدمة. 
المنظمة وكيفية تنفيذها، ويعد السوق الذي تعمل فيه المنظمة والتغيرات الحاصلة فيه من فرص وتهديدات هو نقطة البداية لعملية

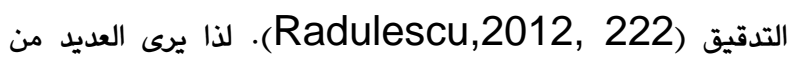
الدارسين بان التدقيق التسويقي يستطيع مساعدة مختلف انواع التنظيمات في مراجعة هياكلها التسويقية وامكانية المساهمة في تبسيط الاعمال على المستوى الكلي وتحسين الاداء الكلي للمنظمة وليس الاداء التسويقي فحسب (Denisa \& Jaroslav, 2013, 27). كما يساهم في دعم التخطيط التسويقي على وجه الخصوص والذي يتطلب منه فهم العوامل ذات العلاقة المباشرة التي تربط بين الزبون والجهود التسويقية للمنظمة كالإعلان، والعلامة التجارية، والتسعير، والترويج (Loya, 2011, 93). ويرى (Köhler, 1993) بان التدقيق التسويقي يعني الاشراف الموجه نحو المستقبل الذي يتعامل مع ظروف او شروط تحقيق النجاح المحتمل. وقد حدد اربعة مجالات له هي كالاتي ( Hajdu,2007 $:(, 269$ الطريقة (الاجراء) - اي عمليات التدقيق الخاصة ب (تأكيد المعلومات، التخطيط واختبار عمليات الرقابة). 1. التدقيق الاستراتيجي - تحليل المقدمات المنطقية، الاهداف الاستراتيجية واتساق الاستنتاجات. 2. تدقيق المزيج التسويقي - فحص كل من القياس والمفهوم الاساسي الاستراتيجي وغرض توافق الادوات. 3. التدقيق التنظيمي - الاخذ الكامل بالحسبان للمهام التسويقية وفحص الصيخ التنظيمية المناسبة ووظائف قواعد التنسيق والتعاون. اما Kotler and Bliemel (2006) فانهما قد ريطا التدقيق التسويقي بالرقابة الاستراتيجية من خلال ستة مجالات توضح مجالات عمل التدقيق التسويقي وهي كالاتي (-267, (Hajdu,2007) 268

Marketing environment تدقيق البيئة التسويقية audit فهم تحليلات البيئة الكلية والجزئية. اذ يجب دراسة عوامل البيئة الكلية من ناحية تأثيرها في مستقبل الشركة. اما على مستوى البيئة الجزئية فيجب اختبار الاسواق والمجهزين وكادر المبيعات والزبائن والمنافسين. وحدة استراتيجية التسويق Marketing strategy Unit: بعد التحليل البيئي فان الخطوة اللاحقة تدقيق استراتيجية التسويق. فمن المهم الاثارة الى فحص الاهداف وكيفية تدقيق التوافق مع اهداف لمان Marketing Organization تدقيق التنظيم التسويقي Audit التأثيرات العملياتية للتنظيم التسويقي. فاذا كان من الممكن يجب
3. المساهمة في تحقيق متطلبات التنمية الوطنية من خلال الارتقاء بالناتج القومي والمساهمة الفاعلة في رفع مستوى تمويل البحث العلمي وتنوعه ويالتالي دعم الدود الريادي للجامعات الوطنية عالمياً.

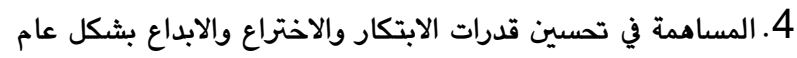
وفي الذدمات الجامعية بشكل خاص ويما يساهم في تحقيق رضا زيائن الجامعة والمستفيدين منها. 5. المساهمة في تحقيق الشعور بالانتماء والانجاز للباحثين واساتذة مينهات الجامعة ويرفع من قيمتهم من خلال جعل اداءهم أكبر من مجرد القاء المحاضرات او القيام بالبحوث التي لا ترى النور. 6.لذا يلعب التسويق الجامعي دوراً مهماً في تطوير الأداء وتحسين جودة الخدمات سواء في الجامعة نفسها او في المنظمات العامة والخاصة المستفيدة من خدمات ويرامج ومخرجات الجامعة في البيئة المحيطة بها (الحريري، 2009 :17)، لذا فان أبرز الامداف العلمية والاكاديمية والاقتصادية لتسويق الخدمات الجامعية كما يراها (باجنيد، 2005) تتمثل بالآتي (العتيبي، 2015 :39): 1. تحسين السمعة الاكاديمية والعلمية للجامعة ويما يساهم في زيادة

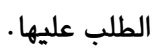
2. تحسين المركز التنافسي للجامعة وادامة القدرة على الاستمرار والبقاء. 3. تحقيق الاستقرار المالي وتحسين ايرادات الجامعة.

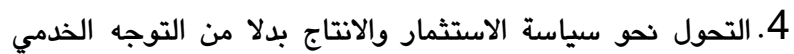
الصرف وتخفيف العبء الاقتصادي عن الدولة. 5. المساعدة على تعزيز مفهوم الاستقلال الجامعي. 2.2 ـ التدقيق التسويقي: يوصف هذا النوع من التدقيق بانه مدخل منظم، وشامل، وهادف، ومستقل له يعمل على مساعدة الادارة في فهم عمل مختلف اجزاء المنظمة ومدى مساهمتها في توجيه النظام الكلي نحو تحقيق اهدافه (Vana \& Cerna, 2012, 131). ويوصف من المنظور الاستراتيجي بانه مراجعة استراتيجية يتم من خلالها التحليل الكافي لقيمة الانشطة التسويقية والمخاطر والكفاءة والفاعلية، في حين يوصف من الناحية الاجرائية بانه فحص شامل ومنظم ومستقل ودودي لمنظمة الاعمال، غرضه تحديد المناطق التي تعاني من المشاكل وتلك التي تمتلك فرص النجاح، واعداد خطة العمل لتحسين الاداء التسويقي للمنظمة (267, Hajdu, 2007. ويالتالي فهو يفطي كل من تقييم حاجات الزيائن وكذلك محاولة فهم نظم المجتمع السائدة (Weingand, 1997, 48). لذا فهو يعد كندي جزءا اساسيا من عملية التخطيط التسويقي، فضلا عن كونه يساعد في جميع مراحل التنفيذ والتقييم للخطط، فهو يستخدم بعض الادوات لتقويم الاداء التسويقي للمنظمة كتحليل (SWOT) وتحليل القوى مرل الخمسة وغيرها (Loya, 2011, 92). ومن ثم فهو يقوم على لئ تحليل وتقويم العوامل الرئيسة المؤطرة للمنطق الاستراتيجي لتسويق 
8. فحص البيئة التسويقية الخارجية والداخلية للمنظمة ومدى

$$
\text { تناسبها مع عناصر الاداء التسويقي. }
$$

9. تقديم خطة مقترحة لتطوير الاداء التسويقي للمنظمة.

10 ـوضع الية للرقابة التسويقية المنهجية.

ويالتالي فان أبرذ منافع ومميزات التدقيق التسويقي تتجلى بالآتي :(Loya, 2011 , 94)

1. يوفر للمسوقين نظرة عميقة لنشاطات التسويق التي تجري في المحيط والتي يسود حولها القلق. اذ انه يظهر او يبرز الصورة الكاملة لكل الانشطة التشغيلية المهمة. اذ كما يساهم في كشف العيوب المختلفة فانه ايضا يقود الى الكفاءة. اذ تستطيع هذه العمليات ايضا ان تستخدم في وضع خطة تسويق محسنة. 2.ان تدقيق تسويقي يمكن ان يساعد في صقل ممارسات الاعمال للشركة وتحسين انتاجيتها ويرحيتها. 3. يساعد التدقيق التسويقي في للمسؤولين التسويقين التنفيذين والادارة العليا والمستثمرين لضمان بأنهم يفعلون الاثياء الصحيحة في المساعدة في تحقيق النمو لمنظماتهم. 4. ان التدقيق التسويقي هو فحص وتقويم متأني للممارسات والنتائج التسويقية. انه يوفر خط الشروع لمقاييس الاداء وأطار عمل لتخطيط الاعمال الفاعل لتعظيم الادراك الخارجي الايجابي وتوليد الطلب. 5. يساعد التدقيق الشركة في تدديد قيمة البيع وقيادة وتوجيه

$$
\text { المبيعات. }
$$

6. ليس هناك اجوية صحيحة دائما في التسويق. فان حاجات الزبائن واراداتهم هي غايات متحركة، وان برامج التسويق تتطلب اختبار واعادة

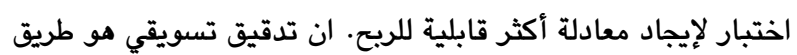
لتحقيق النجاح من خلال توفير تقرير مرحلي لمساعدة الشركة وموظفيها في تعزيز الموارد. 7. ان التدقيق التسويقي غالبا ما يقود الى تغيير التسويق الاستراتيجي. فالتقييم المتأني للتغييرات البيئية والزبائن والقنوات والمنافسين قدي تقود لإعادة تقييم اتجاه المنظمة. ويضع (Cannon, 1968) خمسة مراحل لأداء التدقيق التسويقي كما موضحة بالجدول (1):
الغوص لحذف الانشطة المزدوجة وتقييد الطاقة الاحتياطية وتقليل زمن الانتظار تطوير المنتج المعتد ذاتيا والشؤون المالية. نظام التدقيق التسويقي Marketing audit system: ومنا يتم تنقيح عمليات تشغيل النظام من خلال جمع المعلومات عن السوق ومن خلال التخطيط التسويقي وعلى وجه الخصوص الرقابة التسويقية اذ لا يتم وصف الكفاءة بل كيف يتم تأدية الوظائف. The marketing تدقيق الانتاجية التسويقية productivity audit الانتاجية التسويقية حيث يمكن معرفة كيف يمكن تنظيم تلك التكاليف وماهي النشاطات التي تستهلك الموارد أكثر مما يجب وماهي العمليات

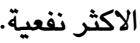
The marketing audit وظائف التدقيق التسويقية functions والتحديد الدقيق لوظائف محددة. لذا يمكن بسهولة تنقية السمات المفقودة التي يمكن الحاجة اليها من قبل الشركة. ومن خلال العرض السابق يمكن تدديد اهم اهداف التدقيق التسويقي تتمثل في (شناي، 2015: 11-12 12:

1. تحديد المكانة السوقية للمنظمة ومنافسيها بطريقة علمية، 2. تقديم التوجيهات والتوصيات بتصحيح أداء عناصر المزيج التسويقي؛ 3. الحكم على الالتزام العام بالتوجه التسويقي للمنظمة، 4. التعرف على مدى تحقيق الاهداف التسويقية الموضوعية والتفاصيل التكتيكية للمنظمة حتى يتم التوصية بما من شأنه تصحيح

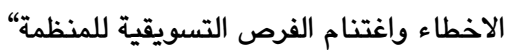

5. المساهمة بصورة أساسية في عملية التخطيط التسويقي" 6. للتطبيق من خلال المكانة السوقية للمنظمة والمركز المالي والإمكانات

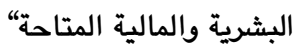
7. اختبار فعالية عناصر الاداء التسويقي والتي تتضمن المزيج التسويقي والإنتاجية التسويقية والنظم التسويقية والهيكل التنظيمي ورسالة المنظمة وأهدافها واستراتيجياتها التسويقية، 
جدول 1: مراحل اداء التدقيق التسويقي

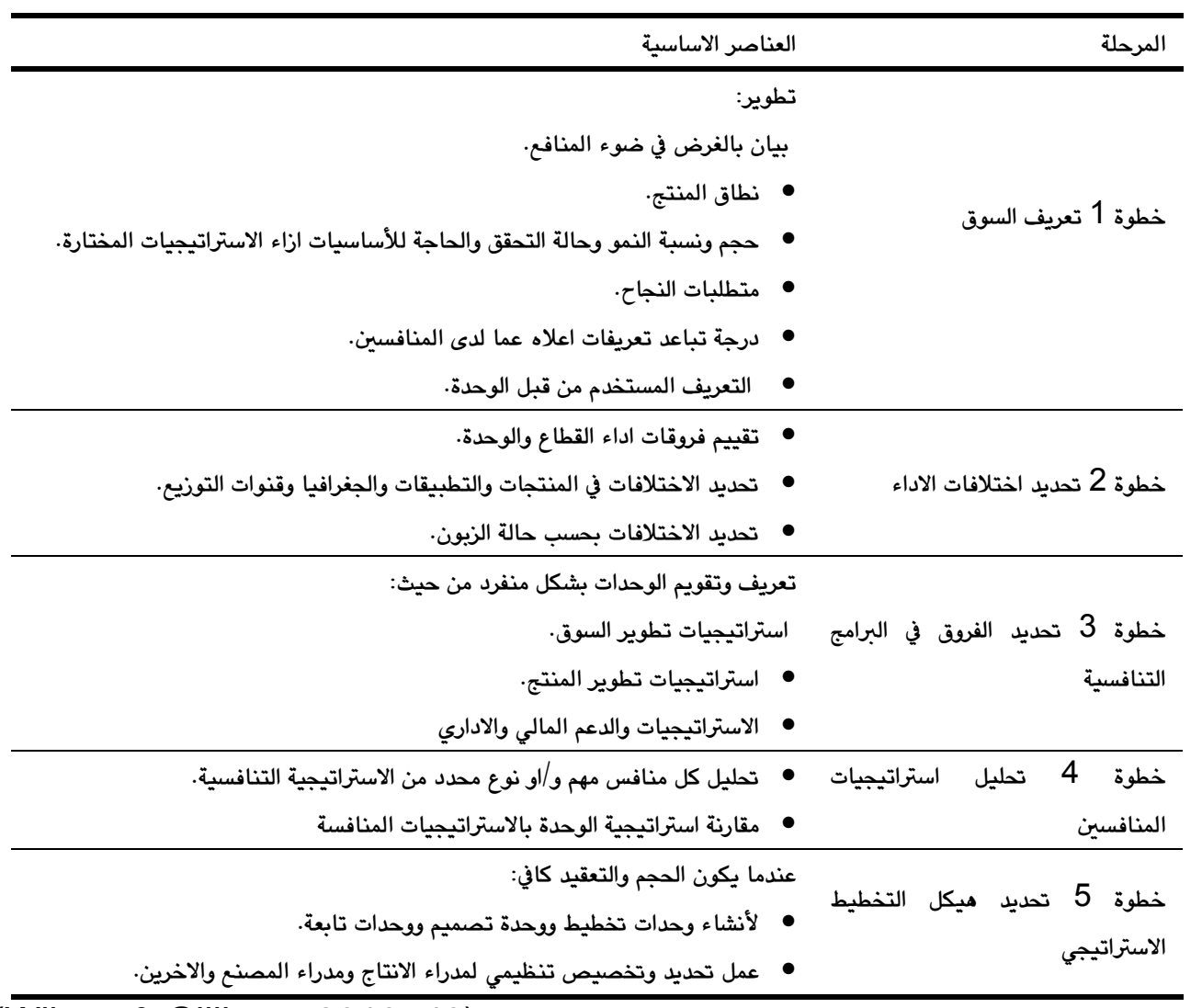

Source: (Wilson \& Gilligan, 2013, 49)

ان من العوامل التي فرضت ضرورة تسويق الخدمات الجامعية والتي يلخص (عزب، 2002) أبرذ تلك العوامل بالآتي (العتيبي، 2015:

الاتجاه العالمي نحو سياسة السوق الحر والخصخصة، مما يساهم في

قدرة الجامعة وخريجيها على مواجهة المنافسة العالمية.

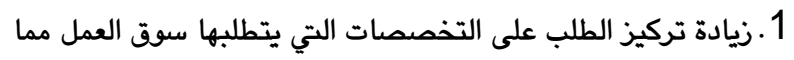
يدعو الى تسويق التعليم لتوفير الموارد والافراد لأنشاء تخصصات مطلوبة. 2.التركيز على العملية التعليمية التي تساهم في اكساب الخريج المهارات التطبيقية بدلا من التركيز على كون التعليم مجرد صناعة،

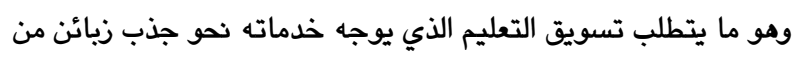
الدارسين جدد باستمرار. 3.ويالتالي فان التدقيق التسويقي يجب ان يبدأ من السوق نفسه كبداية ويجب ان يستكشف التغيرات التي تحدث في السوق ومن ثم التحرك لفحص اهداف واستراتيجيات سوق وتنظيم ونظم الجامعة. وان مداخل وأوجه تطوير تسويق الجامعات المعتمدة ضمن الفلسفة الأمريكية في تسويق الخدمات الجامعية هي كالآتي (راضي وابراهيم،

:(81: 2010
3.2 ـ التدقيق التسويقي وانعكاساته في تفعيل التسويق الجامعي يؤكد العديد من الباحثين على ان أكثر الأنشطة احتياجا لتطوير أدائها

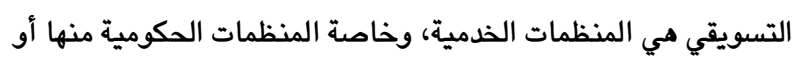
التي لها صفة الاحتكار، ويالتالي فهي بحاجة للاعتماد على التدقيق التسويقي في الرقابة والتقويم لأدائها التسويقي (احمد، 2008 : 2008 : 1:). وتعد تجرية الولايات المتحدة في مجال تسويق الخدمات التعليمية الجامعية من التجارب المتميزة حيث يعتمد التعليم العالي على المنافسة بين الجامعات لاستقطاب وأثارة اهتمام الطلبة والأكاديميين والباحثين ولا تعتبر الرسوم الجامعية ذات تأثير لتوافرها عند الجميع. ومع تطور الجامعات تتطور وسائل المنافسة وتتطور كفاءة الإدارة الجامعية وطرق تسويق الخدمات التعليمية ووفق نموذج التجرية الأمريكية فأن أهم أهداف الخدمات الجامعية ما يأتي (راضي وابراهيم، 2010: 80: 80دوفي أ-إيصال المعلومات عن الجامعة للمستفيدين. ب -إقناع الطلبة للالتحاق بالجامعة وهنا تكمن أهمية طرح المعلومات التسويقية الإقناعية. حيث إن تسويق الخدمات التعليمية يحقق منافع كثيرة منها: أ. نجاح متزايد لرسالة الجامعة التعليمية. ب. تحسين سمعة الجامعة في المجتمع. ت. تحسين وسائل تسويق الجامعات لاجتذاب المزيد من الطلبة. ث. تحسين فاعلية نشاطات التسويق. 
التسويقي كجزء ضرودي من عملية التخطيط التسويقي (McDonald 1984; Kotler 1988; Enis and ان المسالة الرئيسة للاستخدام الحالي يعد Garfein 1992). جزءا من الافتقار لتوحيد واتساق مقبول في الاجراءات والتنفيذ، فهو مكلف ان ينفذ تدقيق شامل ولذلك فانه ريما لا يمكن استخدامه بشكل متسق. (Loya,2011, 96). فيما يؤكد كل من (Chirla \& Funar, 2010) على ان كل منظمة لديها الحرية في الاختيار بين نوعين من التدقيق التسويقي، وان

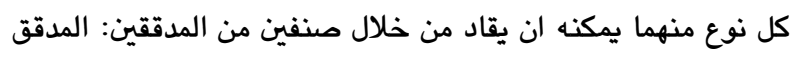

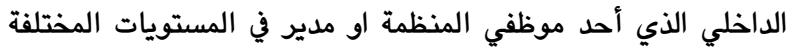

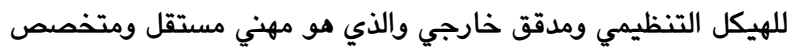
(Denisa \& Jaroslav, 2013,29) مفهوما عمليا للتدقيق التسويقي يفرض وجود بعض المتطلبات التبات

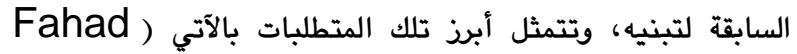
:(et.al., 2015, 217 1 1. وضع اهداف وغايات ورسالة تسويقية محددة. 2. وضع خطة تسويقية واضحة ومجدية.

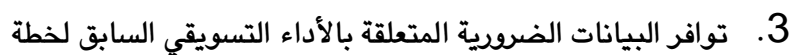
التسويق السائدة. 4. انمان نظام للإبلاغ والمسائلة مناسب. 5. وجود وادامة الادارة على اساس البيانات النظامية. 6. استخدام بعض الادوات مثل تحليل SWOT ونموذج وادمة الادرة القوى

الخمسة لبورتر وتطويرها بما يتناسب وحالة كل منظمة. لذا فان نجاح عملية التدقيق التسويقي تتطلب نجاح عملية التخطيط التسويقي، اذ يعد التدقيق مهما وجزء" حاسماً من عملية التخطيط التسويقي. فالتدقيق التسويقي يمكن ان يؤثر في عملية التخطيط التسويقي خلال مختلف العوامل الداخلية والخارجية. والآتي عدد من الادوات والتقنيات التي تستخدم خلال عملية التخطيط التسويقي لتقويم الاداء التسويقي للمنظمة من خلال التدقيق التسويقي :(Loya, 2011, 97-106) 1. تحليل SWOT: وهو أحد أكثر اهم التحليلات في التدقيق التسويقي فهو يستخدم منذ بداية عملية التدقيق التسويقي، وله مزايا

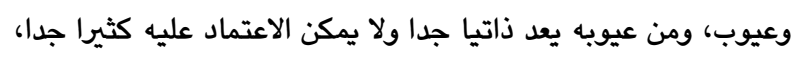
ومع ذلك فان اغلب المنظمات تستخدمه لتقويم الاداء التسويقي. فالتحليل يقوم على القوة والضعف والفرص والتهديدات وان القوة والضعف هي عوامل داخلية فيما تعد الفرص والتهديدات عوامل خارجية. 2. مصفوفة TWOS: ويستخدم المدقق هذا التحليل لتحليل البيئة الخارجية (الفرص والتهديدات) والبيئة الداخلية (القوة والضعف). فالمدقق يمكنه استخدام هذه التقنية للتفكير حول استراتيجية المنظمة
أ-أساسيات التسويق المحلي: ويتضمن التعرف على المجتمع المحلي ويناء علاقات طيبة مع المؤسسات المحلية والمحيطة من تجارية وصناعية. ب -الناحية الإعلامية: وتعني ضرورة تعيين إعلاميين لعمل دعاية والعلان وتعريف بالجامعة. ج-اكتساب محبة المجتمع عن طريق إنثاء قسم خاص ضمن العلاقات العامة لإعطاء صورة مشرقة عن الجامعات ومدى تقديمها خدمات للمجتمع والتوجه لحاجة السوق وهي من المراحل المتقدمة في كيفية ملائمة وتناغم التعليم الجامعي مع المجتمع المحلي أو الوطني أو العالمي. د-بيع النظام ويعتمد على دود الأعلام التسويق من خلال أخصائيين يعتمدون منهجية خاصة في التسويق ويعرضون الصورة الحقيقية

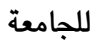
ه-تسويق الجامعة: وفي هذه المرحلة يتم الربط بين إدارة الجامعة وفلسفة التعليم الجامعي والتخطيط المبرمج من خلال تطوير البرامج والدوائر والنظام التعليمي وأثارة الحوار مع المجتمع من اجل الوصول إلى المستفيدين.

فالمدقق التسويقي ريما يتحرك لفحص واحد او اثنين من الوظائف الاساسية التي تعد مهمة للأداء التسويقي للمنظمة بتفصيل أكثر. ليس هناك اجماع لعملية اجراء التدقيق التسويقي، لذلك فان المدققين يحتاجون لتحسين طرق خاصة بهم لأجراء عملية التدقيق استنادا الى مواقف معينة ومهام خاصة تواجههم. فليس هناك محاولة متسقة من قبل الباحثين لتقديم مؤشرات واسعة وعامة لتشجيع التوحيد في تنفيذ التدقيق التسويقي وخصوصا في مجال التسويق الجامعي. فالبعض مثل (Kotler, 1997 ; Brownlie, 1996b) دافعوا عن وفيق استخدام سلسلة من استمارات الاستقصاء في تنفيذ التدقيق التسويقي من خلال جمع معلومات موحدة من المصادر الداخلية والخارجية

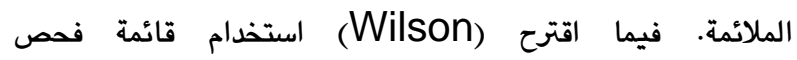
(Checklist شاملة من الاسئلة للتدقيق التسويقي يمكن استخدامها، ولكنه يرى بان يجب على المدقق ان يستخدم قائمة الفحص لجمع البيانات حول

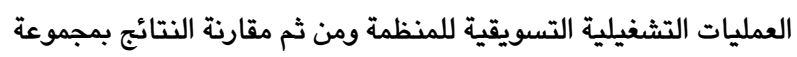
من المؤشرات المرجعية او التوقعات التي يتم تطويرها للقطاع والمنظمة. لذا اعتبرت قائمة الفحص نقطة البداية وتعديل لحالة التصرف حسب المواقف الخاصة السابقة.

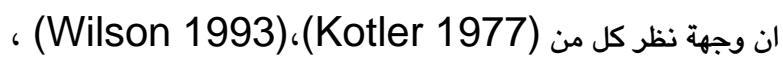
يرون بان التدقيق التسويقي كأداة للحكم (Brownlie 1996)

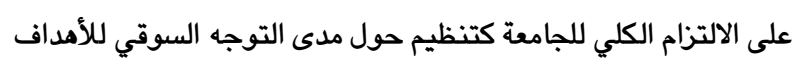
التسويقية التي ثم انجازها بما يتناسب التوجهات الاستراتيجية التسويقية والتفاصيل التكتيكية. فيما يرى اخرون بان التدقيق 
تفعيل وتطوير التسويق الجامعي فقد تم توظيف المنهج المعياري في محاولة للانطلاق من نتائج المنهج الوصفي للوصول الى ما يجب ان يكون عليه التدقيق التسويقي الجامعي الذي يلبي تطوير التسويق الجامعي الكفوء والفاعل. 2.3 . الجامعات العراقية وواقع تسويق الخدمات الجامعية والتدقيق التسويقي 1.2 .3 . تسويق الخدمات الجامعية تمارس الجامعات العراقية مهمة تسويق خدماتها من خلال تشكيل اداري بمستوى شعبة تسمى شعبة تسويق النتاجات العلمية ترتبط فنياً بقسم البحث والتطوير في وذارة التعليم العالي والبحث العلمي، اذ تم استحداث الشعب ضمن مفاصل الهيكل التنظيمي للجامعة والتي ترتبط اداريا بمكتب مساعد رئيس الجامعة للشؤون العلمية بموجب

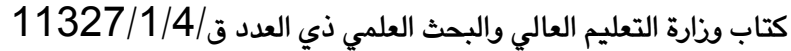
في 2013/5/12. وتضم الشعبة أربعة وحدات هي: • وحدة الصحة والبيئة. • وحدة الدراسات الاقتصادية والاجتماعية والسياسية. • الوحدة الزراعية والبيطرية. • وحدة بحوث العلوم التطبيقية. وتمارس الشعبة المهام والواجبات المرتبطة بعملية تسويق النتاجات

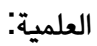

• مليء الاستمارة خاصة بترميز جهات المنشأ للنتاجات العلمية. • استلام النتاجات العلمية وفق استمارة التسويق وتوحيدها وتصنيفها من اجل تسويقها إلى وزارة التعليم العالي والبحث العلمي / دائرة البحث والتطوير / شعبة تسويق النتاجات العلمية.

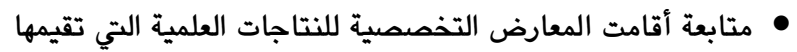
تشكيلات الوزارة ومتابعة الاستفادة منها. • تزويد قسم الإعلام بملخص عن النتاجات العلمية بشكل دوري ومستمر ليتسنى لهم العمل على عرضها في وسائل الإعلام الرسمية كافة • تزويد القناة الفضائية الجامعية بكافة ما يتعلق بالنتاجات العلمية بشكل دوري ومستمر ليتسنى لهم العمل على عرضها في القناة الفضائية. • إنشاء قاعدة بيانات خاصة للنتاجات العلمية ونشرها على الموقع الالكتروني للجامعة على الانترنيت. • إقامة ورثة العمل التعريفية والتثقيفية التي تهدف إلى تقيم والارتقاء بمستوى عملية تسويق المنتجات العلمي. فيما لا يتوفر للقسم والشعب الجامعية رؤية ورسالة واهداف واضحة ومحددة او عملية في مجال التسويق الجامعي. فالأهداف التسويقية الموضوعة تتمثل في (تعمل شعبة تسويق النتاجات العلمية على التسويق الأمثل للاحتياجات العلمية المرتبطة بمشكلات المجتمع وتساهم في حلها وتقدم ما يخدم خطة النهوض في البلد. كما تهدف
ككل او قسم او فريق. كما يمكنه استخدامها في التفكير في العمليات الحملة التسويقية وحتى مهارات المنظمة وتجاربها وخبراتها. لذا فهي تساعد المدقق بالتفكير في الخيارات التي تستطيع المنظمة اتباعها. ولعمل ذلك فان المدقق يقابل المدقق الفرص والتهديدات الخارجية بنقاط القوة والضعف للمنظمة. 3.تحليل PEST: ان التحليل التسويقي يجب ان يأخذ بنظر الاعتبار كل العوامل البيئية ويعطيها التحليل المتأن. ان هذه العوامل البيئية قد تكون داخلية او خارجية، فالعوامل الداخلية تتكون من الموظفون والاستفسارات المتعلقة بهم. والخارجية ستكون الزبائن الخارجيين والموزعين باختلافهم والعوامل السياسية والاقتصادية. ان هذا التحليل له العديد من العوامل التي لها تأثير عمليات التخطيط

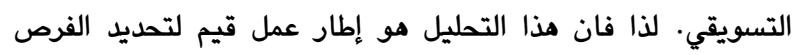
والتهديدات في البيئة الكلية او الخارجية. انه يعمل من خلال مكونات مختلفة من البيئة الخارجية والعلامات التي تنظر المنظمة اليها في مجالات معينة بعمق. ان هذا التحليل مهما جدا لأي عملية تدقيق تسويقي بسيط او معقد والذي يقود المنظمة للتحقق من العوامل التي قد تساعدها او تعرقلها في تنفيذ اعمالها او نشاطاتها التسويقية. 4. نموذج القوى الخمسة: ان هذا التحليل يعد تحليلا فاعلا جدا والذي يمكن المسوق من امتلاك الصورة الواضحة للمنافسة ويستطيع قياس جاذبية القطاع. في هذا التحليل فان المسوق يذهب اساسا للاهتمام بخمسة مناطق اساسية. ان هذه المناطق ان تقسم الى خمسة مناطق من بينها المنافسين وقوة الزبون التفاوضية والقوة التفاوضية للمجهزين. وهناك منافع لهذا التحليل، اذ انه يقود لاقتصاد الحجم

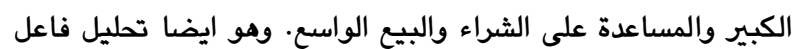
جدا في تدقيق الاداء التسويقي للمنظمة.

\section{3. التدقيق وتفعيل التسويق الجامعي: انموذج مقترح}

1.3. منهج البحث والادوات المستخدمة: يسعى البحث في هذا السياق الى تحديد الملامح الرئيسة لواقع التسويق الجامعي والتدقيق التسويقي في بيئة الجامعات العراقية من اجل وضع انموذج مقترح للتدقيق التسويقي يساهم في تفعيل تسويق الخدمات الجامعية في ظل التوجه العالمي نحو ما يمكن تسميته بالجامعة الاقتصادية وفي ظل خصوصية الازمة الاقتصادية للبيئة المحلية. لقد تم تبني حالة الجامعات العراقية كبيئة للبحث التي لا تختلف بيئتها وملامح ودرجة نضجها التسويقي فيما بينها الى درجة كبيرة. وفي ضوء ذلك فقد ثم توظيف المنهج الوصفي من خلال تحليل محتوى الوثائق الرسمية والنشرات الخاصة بها على مواقع الجامعات العراقية والخاصة بشعبة تسويق النتاجات العلمية لتحديد واقع التدقيق التسويق وتسويق الخدمات الجامعية والوصول الى احكام حول مستويات كل منهما. اما في إطار وضع انموذج مقترح للتدقيق التسويقي يساهم بشكل فاعل في 
من احتياجات فعلية، استلام الاحتياجات الفعلية من الجهة المستفيدة /المستهدفة) بالإضافة الى (اصدار النشرة التسويقية وارسالها عبر البريد الالكتروني، اقامة المعارض التخصصية للنتاجات العلمية بحضور او بالتعاون مع الجهات المستفيدة /المستهدفة، اصدار كراس دوري خاص بالنتاجات العلمية

$$
\text { وتوزيعه ونشره على الانترنت). }
$$

استقطاب الجهة المستفيدة /المحتملة للنتاج العلمي: يتم من خلال صياغة صورة واقعية لجهة المنشأ، وابراز جودة نتاجها العلمي، وطرح الملائم من النتاجات العلمية والترويج عنه، بالإضافة الى استطلاع ما تبحث عنه الجهة المستفيدة /المحتملة واحتياجاتها الفعلية. ويتم ذلك من خلال الوسائل التالية (النشر في وسائل الاعلام، اجراء اللقاءات في القنوات الفضائية، اصدار النشرة التسويقية وارسالها عبر البريد الالكتروني، اقامة معارض عامة للنتاجات العلمية، اقامة المعارض التخصصية للنتاجات العلمية على مامش المؤتمرات والندوات المتنوعة التي تقيمها جهات المنشأ، اصدار كراس دوري خاص بالنتاجات

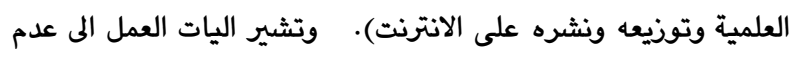
وجود وحدة متخصصة بالتدقيق التسويقي او حتى القيام بنشاطات

تلك الوحدة من قبل الشعبة او افرادها 4. انموذج مقترح للتدقيق التسويقي الجامعي 1.4. اهداف النموذج المقترح ومبراته: يستهدف النموذج وضع دليل مرثد يوضح الجوانب المفاهيمية والعملية لتنفيذ التدقيق

$$
\text { التسويقي الجامعي وكالاتي: }
$$

1. اهداف النموذج على المستوى المفاهيمي: ايضاح المفاهيم الاساسية للتدقيق التسويقي والمساعدة في إدراك الافراد المنفذين والادارة لأهداف وشروط ومتطلبات اداء التدقيق التسويقي. 2. اهداف النموذج على المستوى التطبيقي: وضع دليل لألية تنفيذ العمل التدقيقي التسويقي الجامعي ويما يساهم في شمولية العمل وفاعليته وكفاءته . 2.4 . المفاهيم الاجرائية للنموذج: وكفاعه 1. التسويق الجامعي: وهي العملية التي يتم من خلالها التخطيط والتنفيذ والترويج لما تقدمه الجامعة من خدمات للمستفيدين بهدف اتمام عملية التبادل، حيث يجب ان تتعرف الجامعة على حاجات الاطراف المستفيدة الحالية والمتوقعة من خدماتها والتي يتم تطويرها بما يتفق وحاجاتهم المتغيرة بالشكل والجودة المناسبين وفي الوقت

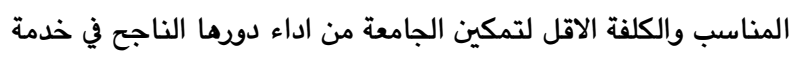

المجتمع. 2. الرقابة التسويقية الجامعية: وهي عملية تحليل نتائج اداء القرارات التسويقية والفرص والتصرفات التصحيحية المتخذة لحل المشاكل او الاستفادة من مزايا الفرص المتوفرة. لذا تعمل الرقابة
شعبة التسويق (والتي تمثل جهة التسويق) وكافة الوحدات المرتبطة بها إلى تسويق النتاجات العلمية كل حسب تخصصس من خلال إيصال النتاجات العلمية التي تنتجها كافة التشكيلات التابعة لوزارة التعليم العالي والبحث العلمي (جهات المنشأ) إلى المجتمع (الجهات المستفيدة) ليتم ربط البحث العلمي بمشكلات المجتمع والعمل على المساممة في حلها وتعمل شعبة تسويق ضمن خطة عمل سنوية). وتخضع النتاجات العلمية القابلة للتسويق للمعايير التسويقية الاتية: 1. ان يكون النتاج العلمي قابل للتطبيق في الظروف الحالية. 2. ان يساهم النتاج العلمي بحل مشكلة حقيقية يعاني منها المجتمع. 3. ان يتضمن النتاج العلمي قيمة علمية مضافة (تطبيقية و/او نظرية).

4. ان يعود النتاج العلمي بفائدة اقتصادية او علمية تخدم خطة النهوض بالبلد.

5. ان يكون النتاج العلمي غير مطبق او مستثمر سابقا لدى دوائر ومؤسسات الدولة.

ويوضح الهيكل التنظيمي الحالي وكما موضح بالشكل (1) موقع شعبة التدقيق التسويقي وروابطه التنظيمية والتي توضح بساطة الهيكل والتي تعكس ضعف الاهتمام ويالتالي قلة الانشطة التسويقية وهو ما ينعكس بشكل واضح في خلو الهيكل التنظيمي من وحدة متخصصة بالتدقيق التسويقي او المسؤوليات الخاصة بأداء انشطة التدقيق. شكل 1: الهيكل التنظيمي لقسم تسويق النتاجات الجامعية المصدر: دائرة البحث والتطوير، وزارة التعليم العالي، استراتيجية

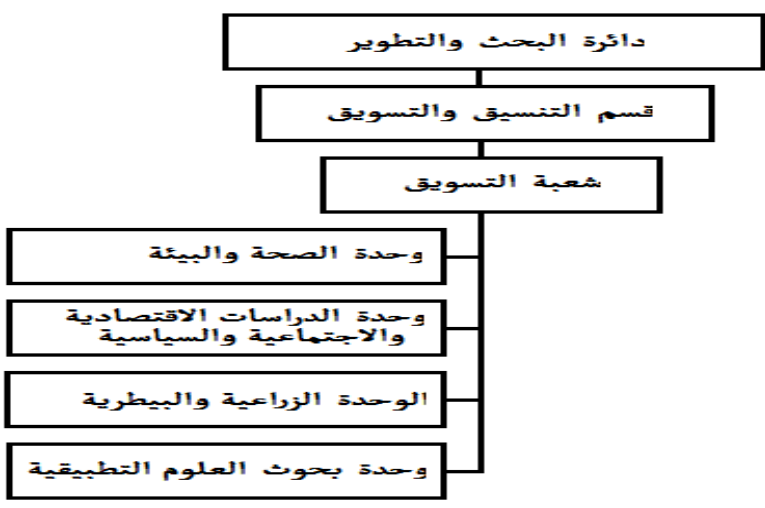

تسويق النتاجات العلمية، 2013. وتتم انشطة التسويق الجامعي وفق اليات عمل تعمل على ايصال المنتجات العلمية من جهات المنشأ الى الجهات المستفيدة ليتم ربط البحث العلمي بمشكلات المجتمع والمساهمة في حلها، وتصنف عملية تسويق النتاج العلمي الى اليتان للعمل هما:

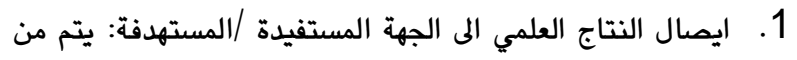

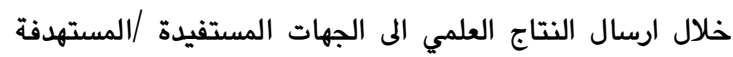
مباشرة. ويتم ذلك من خلال الوسائل التالية (ارسال النتاج العلمي بشكل مباشر الى الجهة المستفيدة /المستهدفة، عقد لقاءات مباشرة مع الجهات المستفيدة /المستهدفة لبيان ما تبحث عنه 
2. الخطط والأهداف التسويقية للجامعة 3. الوظيفة التسويقية للجامعة في مجال المنتج، السعر، الترويج؛ والتوزيع. 4. البيئة التسويقية الكلية والداخلية للجامعة. 5. الإنتاجية التسويقية للجامعة. 6. الهيكل التنظيمي لإدارة التسويق الجامعي. 7. 6.4. مراحل واساليب وادوات التدقيق التسويقي الجامعي: 1.اداء عمليات التدقيق التسويقي: اي كيف يمكننا تدقيق الانشطة والعمليات التسويقية؟ فهناك مهام رئيسية عامة للتدقيق التسويقي هي:

أ. فهم اهداف التدقيق - ما لذي نريد ان نساهم في تحسينه؟

ب. جمع المواد التسويقية - ماذا تستخدم وكيف تستخدمه ؟ ت. المقابلات - التحدث الى الموظفين في كل الاقسام والزبائن اينما يكون مناسباً.

ث. التحليل-ان الفهم والتحليل هو القدرة على توفير المعلومات التي تساهم في توليد نظرة دقيقة ومتعددة الاوجه للوظيفة التسويقية للجامعة. ج. التقارير - اي توفير التقارير الشاملة التي تحتوي على الخطوات التي يمكن اتباعها او استخدامها من قبل الادارة والتي يمكن ان تساعدها في تحسين الوظيفة التسويقية. 1. مراحل اداء عملية التدقيق التسويقي الجامعي: يجب ان تمر عملية التدقيق التسويقي الجامعي بمراحل رئيسية هي: أ. اجتماع المدقق التسويقي بقيادات الجامعة العليا. ب. عرض خطة التدقيق التسويقي واعتمادها. ت. تنفيذ خطة التدقيق التسويقي. ث. صياغة التقرير النهائي للتدقيق التسويقي.

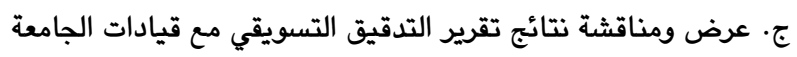
العليا. 2. اساليب اداء عملية التدقيق التسويقي الجامعي: ان

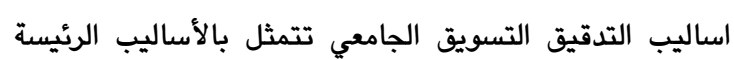

أ. أسلوب قائمة الاستقصاء التي تقدم للمستفيدين. ب. أسلوب قائمة الفحص المشتمل على عناصر التدقيق والتي تقيم بمعرفة المدقق التسويقي. ت. الجمع بين أسلوب قائمة الاستقصاء للعملاء وأسلوب قائمة الفحص للمدقق التسويقي. ويتمثل هذا العنصر في قوائم استقصاء رأي كل من المدقق التسويقي، العملاء، الموظفين بالجامعة. ومن ثم يتم تجميع درجات الترجيح للقوائم الثلاث المشار إليها في قائمة رئيسية واحدة مجمعة للوصول إلى درجة
التسويقية على تأكيد ان العاملين في الجامعة يتصرفون بشكل مناسب للاستراتيجية التسويقية للجامعة. 3. التدقيق التسويقي الجامعي: وهي الاداة الرقابية الاوسع التي تستعين بها الادارة التسويقية الجامعية في التقييم الشامل لكل العمليات التشغيلية التسويقية الجامعية بشكل دوري وثامل والتي تهتم بالجوانب المالية وغير المالية للعمل التسويقي للجامعة. 3.4. اهداف التدقيق التسويقي الجامعي: ان اهم اهداف التدقيق التسويقي تتمثل في: 1. تحديد المكانة السوقية للمنظمة ومنافسيها بطريقة علمية، 2.تقديم التوجيهات والتوصيات بتصحيح أداء عناصر المزيج التسويقي 3. الحكم على الالتزام العام بالتوجه التسويقي للمنظمة، 4. التعرف على مدى تحقيق الاهداف التسويقية الموضوعية والتفاصيل التكتيكية للمنظمة حتى يتم التوصية بما من شأنه تصحيح الاخطاء واغتنام الفرص التسويقية للمنظمة، 5. المساممة بصورة أساسية في عملية التخطيط التسويقي" 6. تطوير الحلول التسويقية ذات الفعالية في التكلفة والقابلة للتطبيق من خلال المكانة السوقية للمنظمة والمركز المالي والإمكانيات البشرية والمالية المتاحة، هُ 7. اختبار فعالية عناصر الاداء التسويقي والتي تتضمن المزيج التسويقي والإنتاجية التسويقية والنظم التسويقية والهيكل التنظيمي ورسالة المنظمة وأهدافها واستراتيجياتها التسويقية،

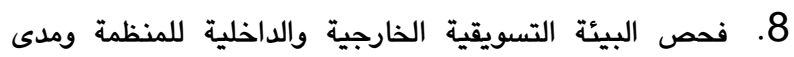
تناسبها مع عناصر الاداء التسويقي. 9. تقديم خطة مقترحة لتطوير الاداء التسويقي للمنظمة. 10 ـوضع الية للرقابة التسويقية المنهجية. 4.4. المتطلبات السابقة لوجود التدقيق التسويقي: بغرض

ايجاد تدقيق تسويقي ناجح يجب تهيئة المتطلبات السابقة الاتية: .وضع رؤية ورسالة واهداف تسويقية محددة للجامعة.

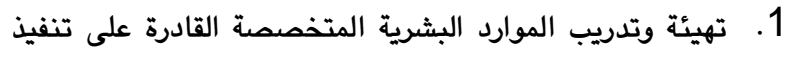
متطلبات التدقيق التسويقي الجامعي. 2. وضع خطة تسويقية واضحة واقتصادية وسليمة معتمدة على قواعد بيانات تسويقية عن الاداء السابق. 3. انشاء نظام للتقارير والمسائلة واضح ومناسب. 4. استخدام ادوات مثل تحليل SWOT ونموذج القوى الخمسة لبورتر وتطويرها بما يتناسب وحالة الجامعة. 5.4 . عناصر التدقيق التسويقي : إن عناصر التدقيق التسويقي التي يجب توافرها في التسويق الجامعي الناجح يجب ان تشتمل على الآتي: 1. رسالة ورؤية واستراتيجية الجامعة التسويقية. 
الجغرافية بما يمكن تسميته نظم المعلومات الجغرافية للعملاء كأسلوب يسهل تفهمه والاستفادة منه من خلال الإدارة العليا. موقع التدقيق التسويقي في الهيكل التنظيمي: إن أهمية التسويق بالنسبة للجامعات بصورة خاصة كأهمية الجهاز العصبي والحواس الخمسة للإنسان في الاتصال من وإلى الآخرين، لان الزيون يلتقي مباشرة بجميع أطراف العملية البيعية حيث يمثل له مؤدي الخدمة في هذه الحالة بمثابة المنتج والبائع والموزع وهو الأمر الذي يصعب وقد يستحيل في تسويق السلع، ويمعنى آخر يعتبر تسويق الخدمات أدق اختبار لمدى نجاح الأداء التسويقي بالجامعات كمنتج للخدمات. ومن هذا المنطلق ويغرض تفعيل الهياكل التنظيمية للتسويق بالجامعات هناك ضرورة لتخصيص إدارة للتدقيق التسويقي تتبع مباشرة الإدارة العليا للجامعة لتقوم بدعم القرارات التسويقية الاستراتيجية للجامعة، ويتبع هذه إهـاء الإدارة عدة وحدات تتضمن الوحدات الرئيسية التالية: 1. وحدة تصميم وتجميع وتحليل البيانات الإحصائية.

$$
\begin{aligned}
& \text { 2. وحدة قواعد المعلومات والحاسب الآلي. } \\
& \text { 3. وحدة تقارير التدقيق التسويقي. } \\
& \text { 4. وحدة الاستخبارات التسويقية. } \\
& \text { 5. وحدة الذكاء الصناعي والحلول البديلة. }
\end{aligned}
$$

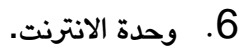

لذا فان من الضروري عدم تبعية وحدة التدقيق التسويقي نهائيا للإدارة العامة للتسويق بالجامعة حيث يشترط وفقا لمعايير التدقيق الدولية أن يكون هناك استقلال مهني بين التنفيذ والتدقيق. كما يجب أن تكون هناك رقابة خارجية تقوم بالتدقيق التسويقي على فترات متباعدة من خارج الجامعة وغير مرتبطة بإدارة وحدة التدقيق التسويقي الداخلية. تقارير التدقيق التسويقي: تتضمن تقارير التدقيق التسويقي ما قام به المدقق من اعمال بشكل تفصيلي والفترات الزمنية ونتائج التحليل الإحصائي والاستقصائي مشيرا إلى الإحصاءات المقارنة سواء الخاصة بالسنوات السابقة أو الخاصة بالمنافسة والقطاع ، ثم يختتم التقرير بالتوصيات التي سيتم تتبعها بالتقرير اللاحق. كما يجب ان تقدم تلك التقارير بشكل دوري منتظم فضلا عن التقرير الختامي السنوي بجانب التقارير الطارئة التي قد يتطلب تقديمها في الظروف غير الاعتيادية. كما يمكن للإدارة العليا الاستعانة بأحد المختصين بالتدقيق التسويقي من خارج الجامعة لتقديم تقرير تدقيق سنوي عن الأداء التسويقي العام للجامعة بما في ذلك وحدة التدقيق التسويقي الداخلية

\section{5. الاستنتاجات والتوصيات}

1.5 - 1.5 - الاستنتاحات

اهمية التدقيق التسويقي ومنافعه الكبيرة في تفعيل تسويق المنتجات الجامعية من خلال تعميق إدراك الادارات الجامعية بمفهوم وتطبيقات
التدقيق التسويقي التي تحول بعد ذلك إلي نسب مئوية من إجمالي الدرجة القصوى للقائمة الرئيسية. وخلال ذلك يمكن أيضا استخدام الاساليب الفرعية الاتية: أ. قائمة الاستقصاء للتسويق الداخلي لموظفي الجامعة. ب. قواعد البيانات الإحصائية للإنتاجية التسويقية. ويمثل هذا العنصر التحليل الإحصائي لقواعد البيانات التسويقية وتحليلات السلاسل الزمنية والتحليلات المقارنة بين الجامعة وبيانات قطاع الجامعات الذي تنتمي إليه، وتجدر الإثارة إلى أن مذه التحليلات لا يشترط أن تكون بعد مضي فترة من مزاولة النشاط بل قد تكون قبل مزاولة النشاط ويفضل أن تحول كل الأرقام إلى صورة نسب مئوية ليسهل تتبعها بالسنوات اللاحقة. 3. ادوات تنفيذ عملية التدقيق التسويقي الجامعي: مناك عدد من الادوات والتقنيات التحليلية النافعة خلال التدقيق التسويقي: تحليل SWOTويستخدم في بداية عملية التدقيق التسويقي لتقويم الاداء التسويقي. أ. مصفوفة TWOS وتستخدم لتحليل البيئة الخارجية (الفرص والتهديدات) والبيئة الداخلية (القوة والضعف). ب. تحليل PEST ويستخدم في تحديد الفرص والتهديدات في البيئة الكلية او الخارجية. اذ يعمل من خلال مكونات مختلفة من البيئة الخارجية والعلامات التي تنظر الجامعة اليها في مجالات معينة بعمق. ان هذا التحليل مهما جدا لأي عملية تدقيق تسويقي بسيط او معقد والذي يقود الجامعة للتحقق من العوامل التي قد تساعدها او تعرقلها في تنفيذ اعمالها او نشاطاتها التسويقية. ت. نموذج القوى الخمسة يساعد هذا التحليل في امتلاك الصورة الواضحة للمنافسة ويستطيع قياس جاذبية القطاع حيث يقوم على الاهتمام بخمسة مناطق اساسية من بينها المنافسين وقوة الزبون التفاوضية والقوة التفاوضية للمجهزين. كما يجب أن تتضمن قواعد البيانات التسويقية المشاهدات الإحصائية عن الأداء التسويقي كلما زاد ذلك من إمكانيات دقة التدقيق التسويقي ودعمها لمتخذ القرار. والاهتمام بتوظيف النظم الالكترونية للاستفادة من إمكانيات تحليل البيانات الكبيرة بسرعة عالية وجودة تحليل فعالة يصعب الوصول إليها بالتشغيل اليدوي. فضلا عن اممية اجراء عمليات التدقيق التسويقي المتتابعة وخرائط السلاسل الزمنية لتلك العمليات وقياس مدى التطور التسويقي للجامعة نحو الوصول للمكانة السوقية الأفضل. كما لابد من تحليل العملاء بحسب الأممية النسبية لكل قطاع من العملاء، وتختلف الأهمية النسبية بحسب الاستراتيجية التسويقية، فمثلا قد تستهدف الجامعة العملاء الجدد ويالتالي تزيد أهميتهم النسبية، مذا بجانب الاهتمام المستمر والمنتظم لمتابعة درجة رضا كبار العملاء .ولابد من إتباع أساليب القطاعات للعملاء على الخرائط 
6. التصدي للمعوقات التي تواجه تسويق الخدمات الجامعية وأهمها ثقافة الفكر التسويقي لدى الجامعات وأعضاء هيئة التدريس والعاملين

7. الاستفادة من تجارب الجامعات العالمية في تسويق خدماتها بما يتناسب مع البيئة العراقية وفى ضوء الإمكانات المتاحة. 8. نشر ثقافة تسويق الذدمات الجامعية بين جميع العاملين في الجامعة حتى يصبح التسويق منظومة عمل. 9. إعادة النظر في القوانين بهدف إعطاء المرونة للجامعات في التعامل مع الاطراف المختلفة تسويقياً. اجراء البحوث والدراسات التسويقية للتعرف على احتياجات ورغبات العملاء ومدى رضاهم عن الخدمات المقدمة.

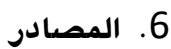

1.6 دائرة البحث والتطوير، وزارة التعليم العالي، استراتيجية تسويق النتاجات العلمية، 2013

المواقع الالكترونية للجامعات العراقية، شعبة تسويق النتاجات الجامعية.

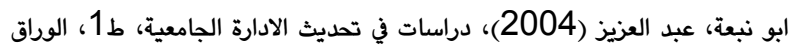
للنشر، عمان. احمد، اسامة (2008)، المراجعة التسويقية، مجلة التدريب والتقنية، العدد (84)، 0/2008http://osamamarketing.blogspot.com/

.html49/8

احمد، بله احمد بلال (2010)، تسويق خدمات المعلومات في المكتبات، جامعة السودان المفتوحة. ous.edu.sdww

الحريري، خالد حسن علي (2009)، التوجه التسويقي في مؤسسات التعليم الاداري

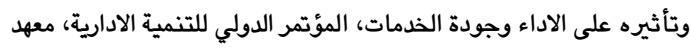
الادارة العامة، المملكة العربية السعودية.

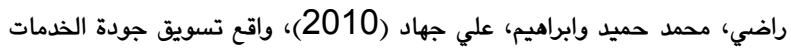
التعليمية، مجلة الادارة والاقتصاد، العدد 85، العباد العراق.

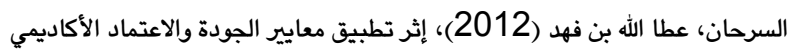
على تسويق مخرجات التعليم في الجامعات السعودية، المؤتمر العربي

الدولي الثاني لضمان جودة التعليم العالي، المملكة العربية السعودية.

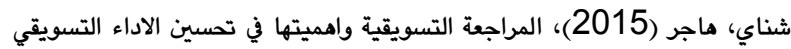
للمؤسسات الخدمية، رسالة ماجستير، جامعة قاصدي مرباح، الجزائر. الضمور، هاني حامد والشمايلة، حمزة نبيه (2007)، التوجه التسويقي لدى

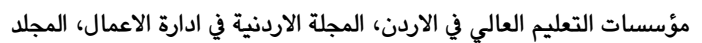

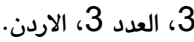

العتيبي، بدر مبروك (2015)، تسويق الخدمات الجامعية ودوره في تحسين القدرة

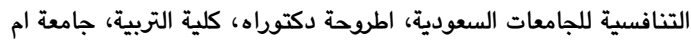
القرى، المملكة العربية السعودية.

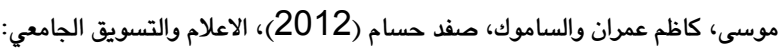

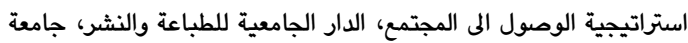

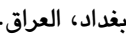
2.6

Al Fahad, Abdullah, Abdul Rahman, Al Mahmud, Robel Miah, and Ummay Hani Islam, (2015),
ومنافع التسويق الجامعي ودوده في دعم متطلباتها في الاستقلال

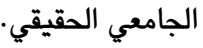
1. ضعف دور الادارة التعليمية العليا للحكومة في وضع رؤى واضحة وقواعد عمل وسياسات تحفز وتشجع وتطور من قدرات الجامعات في تبني مفهوم وسياسات واضحة للجامعة الاقتصادية ومتطلبات تسويق المنتجات الجامعية واليات تنظيمه وتفعيله.

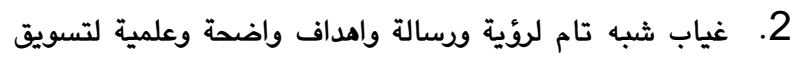
المنتجات الجامعية في بيئة الجامعات العراقية تعكس وضوح وامتمام الجامعة بالنشاط التسويقي المطلوب والياته ويرامجه.

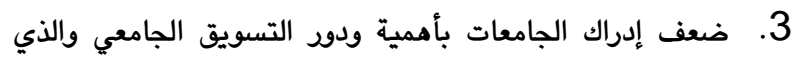
يتضح جليا في ضآلة دورها وادواتها وخططها او تطوير منتجاتها التسويقية، وغياب رؤية واضحة في مذا الجانب على الرغم من ادراكها لحجم الازمة المالية التي تمر بها واستمرارية رغبتها بالاعتماد على التمويل الحكومي. 4. غياب تام لمفهوم التدقيق التسويقي او دوره والياته واهميته في نجاح وتفعيل خططها التسويقية ورغبتها في تفعيله ونجاحه. 5. غياب ثقافة الفكر التسويقي لدى الادارات الجامعية نتيجة الاعتقادات الراسخة لديهم بأن المؤسسات الجامعية لا تخضع للقوانين التسويقية التجارية. 6. غياب التمويل اللازم لتأهيل وانشاء مراكز تسويقية بالشكل الذي يتناسب وتوقعات وطموحات العملاء المستفيدين. 2.5 1.ضرودة تبني النموذج المقترح للبحث الحالي في مجال التدقيق التسويقي والذي يوضح مفهومه واهدافه وتنظيمه والياته وادواته ويما يشكل دليل عمل متكامل للتطبيق ويما يساهم في تفعيل مهمة الجامعة التسويقية ومواجهة المنافسين. 2. اقتراح تأسيس مركز لتسويق المنتجات الجامعية متخصص في كل جامعة يتولى مهمة التسويق الجامعي وفق الاصول العلمية والعملية وتوفير الدعم الكافي لتفعيل المركز من الموارد البشرية والمادية يسمى مركز تسويق المنتجات الجامعية. 3.ضرورة تبني الجامعة لرؤية ورسالة واهداف تسويقية مدروسة وواضحة تحدد فيها ملامح استراتيجيتها التسويقية. 4. مراعاة التسويق الداخلي أي تحقيق القناعة الداخلية بين الموظفين بالتوجيهات التسويقية للجامعة والاستفادة من آراء الموظفين منعا لحدوث ما يسمي بالتسويق السلبي والذي يكون فيه توجهات الموظفين ضد السياسات التسويقية للجامعة. 5.ضرورة توافق الفكر التسويقي للجامعة والسياسة العامة للدولة وتوظيف التدقيق التسويقي في الرقابة على الأداء التسويقي وخصوصا في مجال تدقيق تسويق المفاهيم والذي قد يكون وسيلة ناجحة في اكتشاف وحل كثيراً من المشكلات العصرية ومنها الإرهاب وغيرها. 
Multidisciplinary Management Studies Vol. 1 Issue 2, Indore, Madhya Pradesh, India. November, http://zenithresearch.org.in/

Radulescu, Violeta (2012), The Role of Market Analysis in Developing Efficient Marketing Audit, International Journal of Academic Research in Economics and Management Sciences , Academy of Economic Studies, September, Vol. 1, No. 5, Bucharest.

Vana, kamil \& Černa, lubica (2012), the marketing audit as a method of the evaluation of the marketing plan, Faculty of materials science and technology in Trinova, Slovak university of technology in Bratislava.Weingand, Darlene E., (1997), The Marketing Audit Using Systems Analysis to inform market Research, American library association, USA.

Wilson, Richard M.S. and Gilligan, Colin, (2013), Strategic marketing management, 3d. ed., Routledge publishing, USA
Marketing Audit: A Systematic and Comprehensive Marketing Examination, International Journal of Scientific and Technology Research, Vol. 4, Issue 07, JULY.

Chirla, EC.Gabriala Ofelia, (2012), marketing audit in the agro food industry, $\mathrm{PhD}$. Thesis, University of Agricultural Sciences and Veterinary.

Denisa, Lipincka and Jaroslv, Dado, (2013), marketing audit and factors influencing its use in practice of companies: from an expert point of view, journal of competitiveness, vol.5, issue four.

HAJD, Noémi (2008), Theoretical Background of Marketing Audit, Economics Questions, Issues and Problems, University of Miskolc, Miskolc, Hungary.

Hutt, Michael \&, Speh, Thomas, (2010), Business marketing management, 10ed. South- western cangage learning, USA.

Loya, Arpit (2011), Marketing Audit- An Important Tool to Determine Strengths and Weaknesses of the Companies, International Journal of 


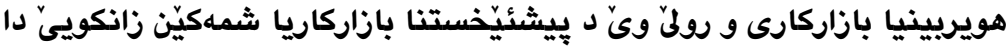

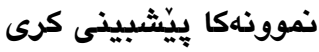

ليَكولينا به رده ست بخو ثه دكريت جهه مك و يِراكتيكيّن هويربينيا بازاركارى لريكخراويّن خزمهت كوزارى يِين نَارمانجا وان نه قازانج

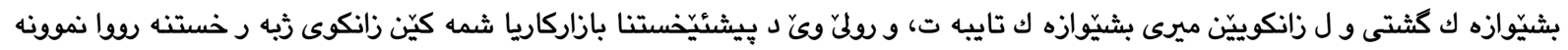

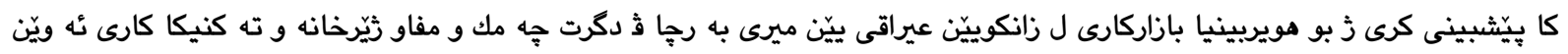

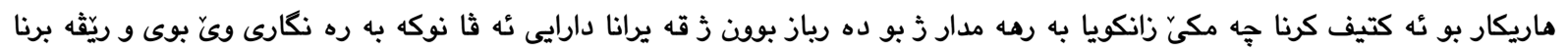

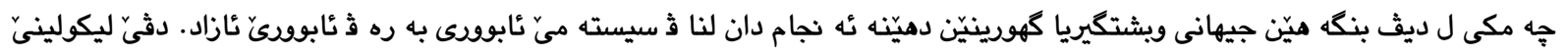

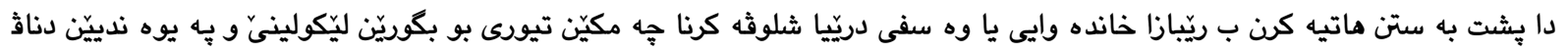

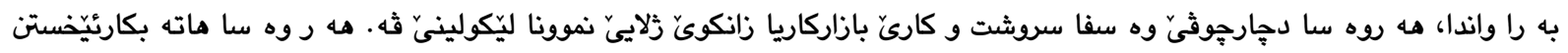

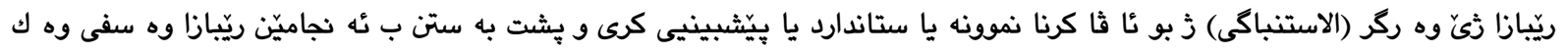

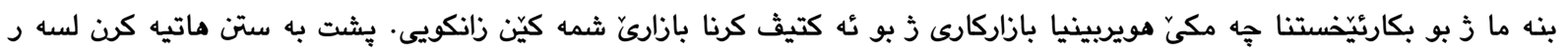
زانكوييّن عيراقى وه كو نموونا ليّكولينا وه سفى دريّيا كومكرنا داتاييّن كريّداى ب بازاركارىّ زانكوى يِين ئه ثرو وهوير بينيا بازاركارى بريّيا

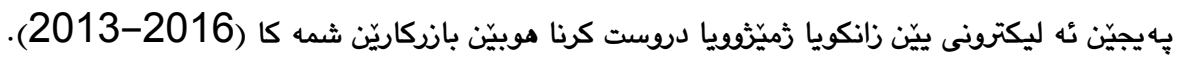

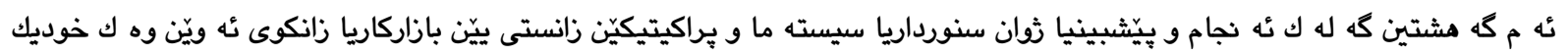

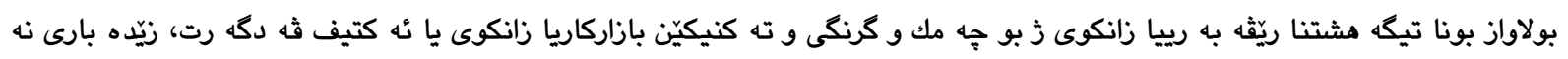

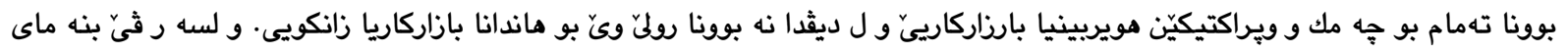

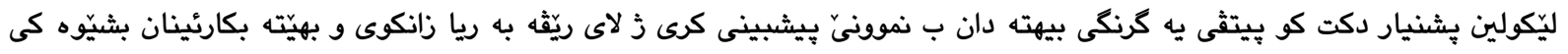

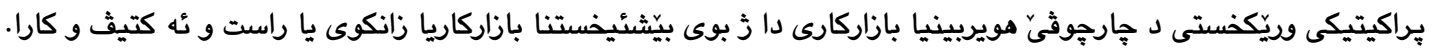

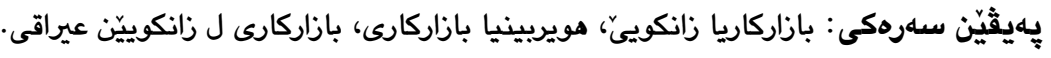

\section{Marketing Audit and Its Role in Improving the Marketing of University Products} A Proposed Model

\begin{abstract}
:
The current research tackles the concept and applications of marketing audit in the non-profit service organizations in general and in public universities in particular, and its role in improving the marketing of university products with the aim of presenting a proposed model for the marketing audit in Iraqi public universities. Which tackles concepts, benefits, structures, and work mechanism, which contribute in activating the concept of productive university to bypass the financial crisis that confront it currently and to copy with this concept globally and support the shift in Iraqi economic system toward market economic.

In this context, it has been adopted inductive descriptive approach through study and analyzes theoretical concepts of research variables and relationship between them, and describe the nature and practices of marketing audit in field of research sample. As, it has been employing the deductive approach to constructing a proposed normative model based on the results of the inductive approach as a basis for employing the concept of marketing audit in activating marketing of university products. Therefore, it has been selected the Iraqi universities a sample of the descriptive study through collect the data regards to the current reality of university marketing and marketing audit by universities websites for period between the date of establishing unit of marketing (2013) to the year (2016).

It was reach several conclusions, notably the limited systems and scientific applications for university marketing. Which reflects the weak awareness of the university administration with the concept and the importance and mechanisms of effective university marketing, as well as the complete absence of the concept and applications of marketing audit and therefore the absence of his role perfectly in university marketing support. Therefore, it was recommended Current search the need to pay university administration proposed model applied and regulatory importance in the field of marketing audit to contribute to the development and university marketing real, effective and efficient.
\end{abstract}

Keywords: University Marketing, Marketing Audit, Iraqi Public Universities. 